\title{
Research Paper: Review and Comparison of Content Growth in Word Definition of Persian Speaking Children of 7-12 Years of Age
}

\author{
Shima Matloubi ${ }^{1}{ }^{\oplus}$, *Talieh Zarifian ${ }^{1}$, Tahereh Sima Shirazi ${ }^{1}$, Enayatollah Bakhshi
}

1. Department of Speech Therapy, University of Social Welfare and Rehabilitation Sciences, Tehran, Iran.

2. Department of Biostatistics, University of Social Welfare and Rehabilitation Sciences, Tehran, Iran.

Received: 03 Jul. 2017 Accepted: 10 Dec. 2017

Keywords: Word definition Development, Student, Semantic, Metalinguistic dtation: Matloubi Sh, Zarifian T, Sima Shirazi T, Bakhshi E. [Review and Comparison of Content Growth in Word Definition of Persian Speaking Children of 7-12 Years of Age (Persian)]. Archives of Rehabilitation. 2018; 19(1):4-17. https://doi. org/10.21859/JREHAB.19.1.4

https://doi.org/10.21859/JREHAB.19.1.4

\begin{abstract}
Objective Language has three components: content, form and pragmatic. The content includes the semantic components. Semantic knowledge of word relationships requires awareness of the relationships between different words in the same field and other fields. One of the main components of the semantic is the mental lexicon that many of the semantic communications, including the organization and semantic representations of words, take shape in this network. The important issue is how to organize words in mind, linking the words together and their position in the semantic network. One task that helps to organize the meanings of the words in the mental lexicon is the word definition task. The ability to define words is reliant o several aspects of linguistic and metalinguistic development, literacy, and academic achievement. The aim of this investigation was to study the definitional style of nouns in typically developing school-aged children.

Materials \& Methods In this cross-sectional and descriptive-analytical study, 150 typically developing school-aged children, selected using multistage sampling method, studying in the second to sixth grades in 1, 7 and 17 municipal districts of Tehran were included. The definition skill was assessed with word definition task. The students were asked to define the words, and their answers were scored based on content. The reliability was assessed by two independent values, and the validity was determined by the content. The results were analyzed by the SPSS V. 22 software using the methods of independent- samples T test, univariate analysis of variance and Tukey's test.

Results The findings showed that by increasing the age, the noun definitions were developed from functional and concrete responses into combination two and using of superordinate terms were increased. The mean score of the content in word definition was significantly increased by age $(P<0.001)$. Also the performance of girl students was better as they earned higher scores than the boys $(P=0.03)$.

Conclusion On increasing the age, the content quality of word definitions improved significantly. The concepts were found to be organized into hierarchies of connections. Also, definitions were developed from functional and concrete responses into combination two and formal responses. And finally, the word definition task can be used by speech and language therapists in clinical and educational environments.
\end{abstract}

\section{* Corresponding Author:}

Talieh Zarifian, PhD

Address: Department of Speech Therapy, University of Social Welfare and Rehabilitation Sciences, Tehran, Iran.

Tel: +98 (21) 22180043

E-Mail: t.zarifian@yahoo.com 


\title{
بررسى و مقايسه رشد جنبه محتوايیى مهارت تعريف وارَه در دانش أموزان V تا I ا ساله فارسىزبان
}

\author{
شيما مطلوبى '0، "طليعه ظريفيان'، طاهره سيما شيرازى'، عنايتالله بخشى'
}

ا - كروه كفتاردرمانى، دانشكاه علوم يهزيستى و توانبخشى، تهران، ايران.

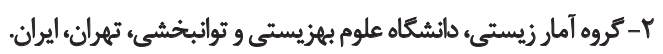

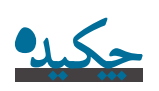

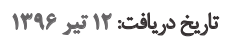

تاريخ بذيرش: 19

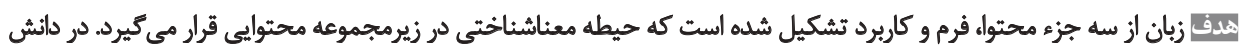

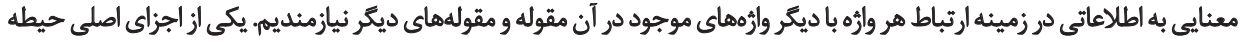

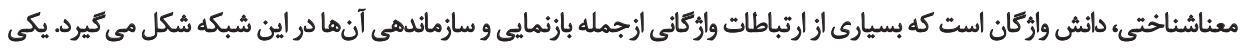

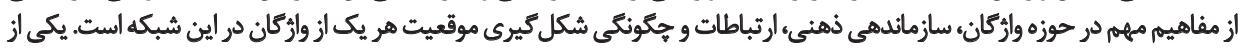

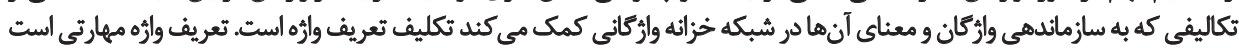

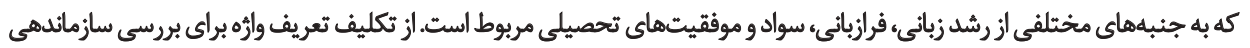

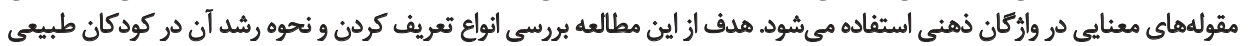

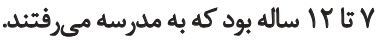

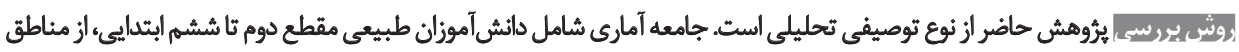

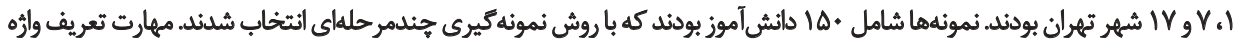

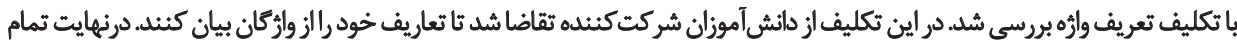

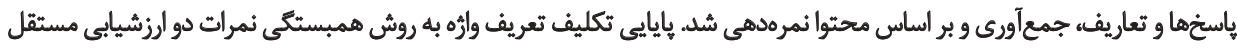

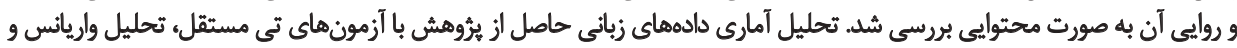

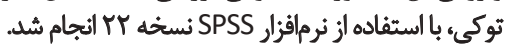

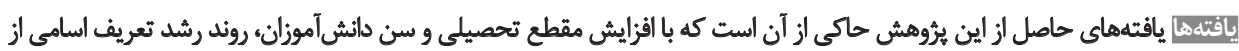

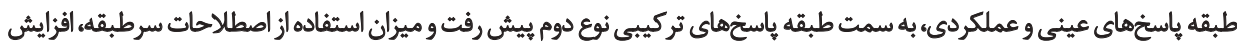

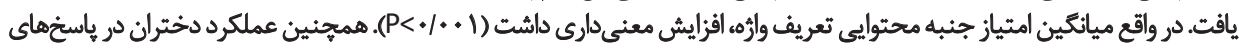

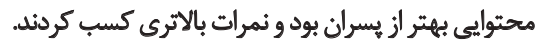

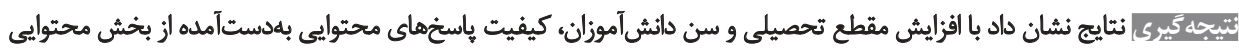

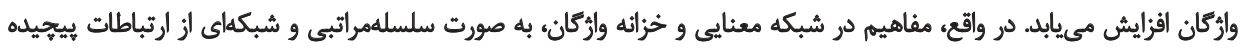

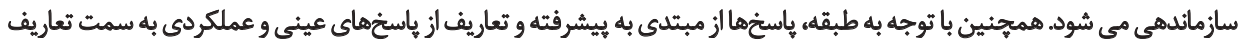

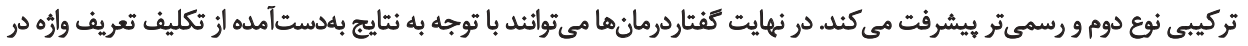
محيطهاي آموزشى و بالينى استفاده كنيند.

: Loglguts

تعريف وائه، رشد، دانشيآموزء معناشناسي، رشاني فرازبانى

دانش معناشناختى به ذخيره وازّكان هر فرد، اشياء و رويدادهاى

مقدمه

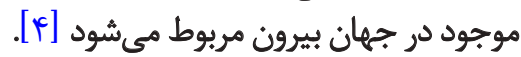

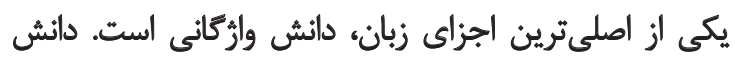

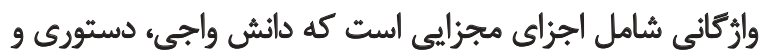

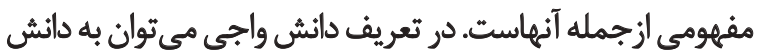

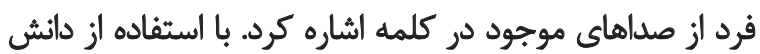

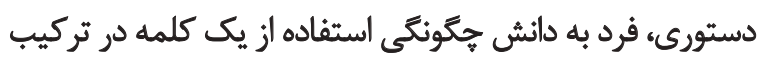

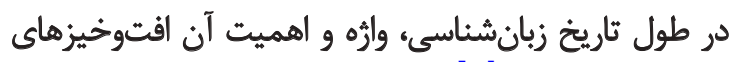

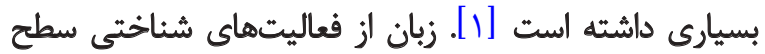

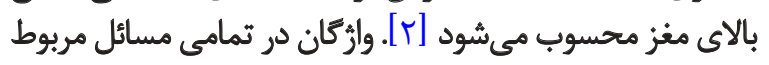

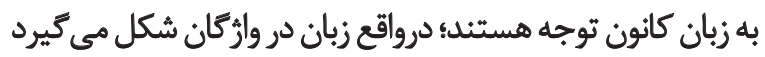

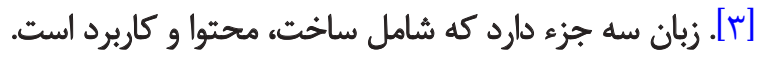

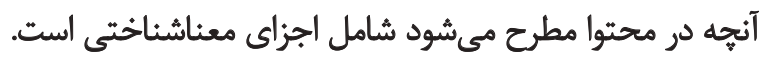

\section{ㅁ.}


دستيابي به آن را تسهيل ميى كند. در واقع مقولهبندى ازجمله

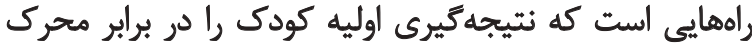

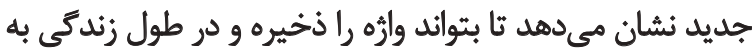

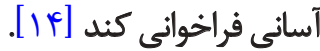

روند رشد معنا به شكلى است كه از قالبهاي عينى و عملكردى

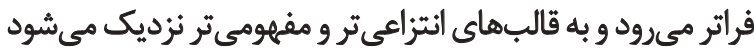

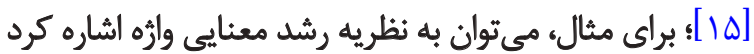

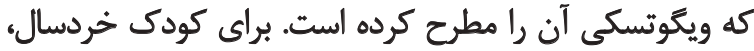

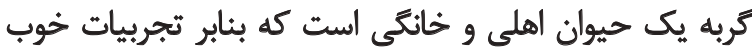

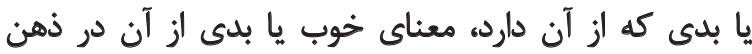

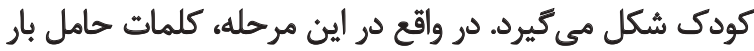

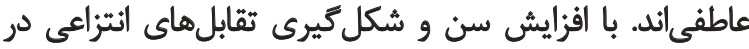

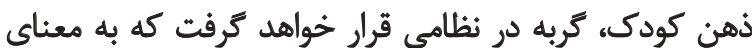

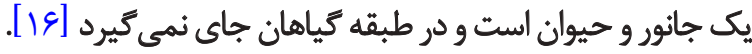

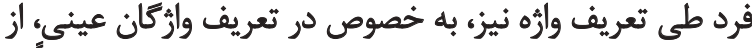

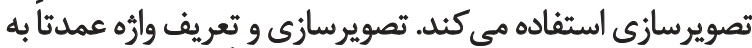

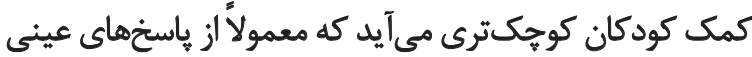

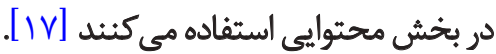

مطالعات زيادى در حوزه مهارت تعريف واره انجام كرفته است

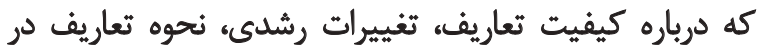

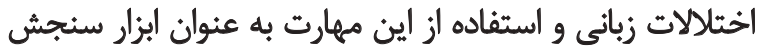

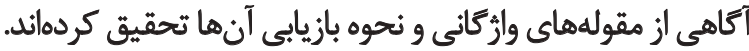

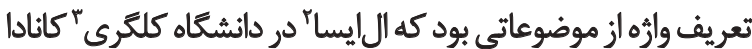

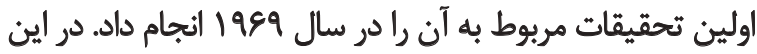

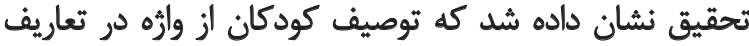

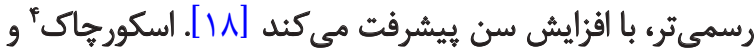

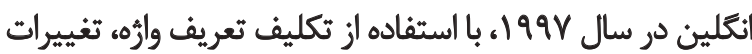

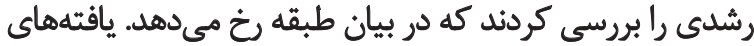

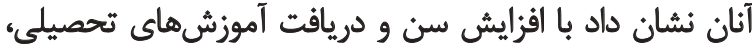

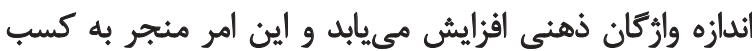

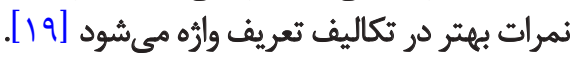

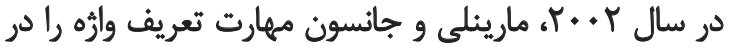

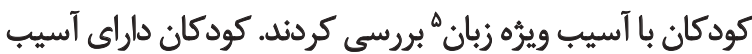

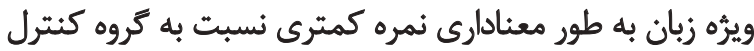

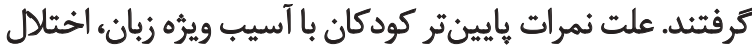

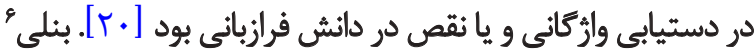

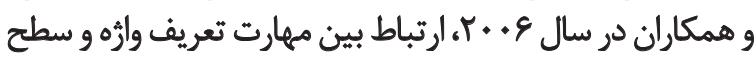

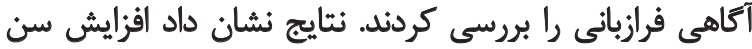

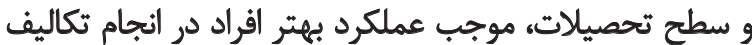

\section{Al-Issa}

3. University of Calgary

4. Skwarchuk

5. Specific language impairment (SLI)

6. Benelli
با كلمات ديكُ مىرسد. دانش مفهومى نيز تعريف واردكان را شامل

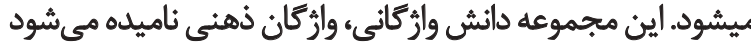

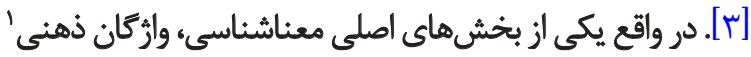

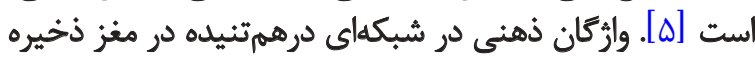

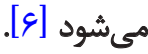
خزانه واثَّانى، در تمام طول زندگتى فرد، در حال رشد و تكامل

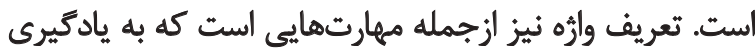

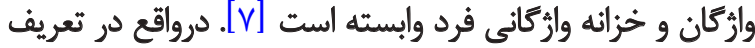

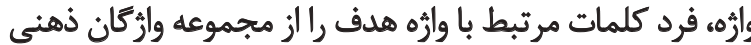

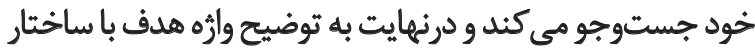

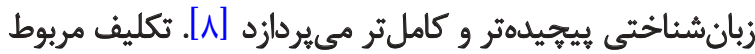

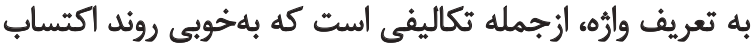

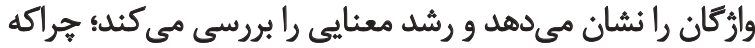

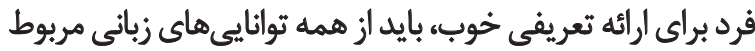
به درك و توليد خود استفاده كند [9] بائ.

همه تعاريف دو جزء محتوا و ساختار را شامل مىشوند [. [1].

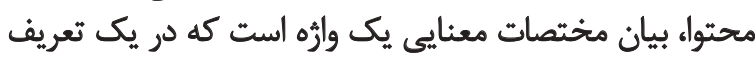

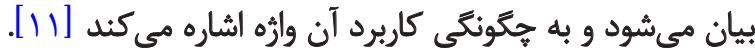

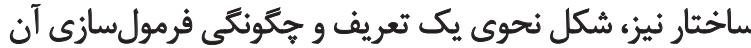

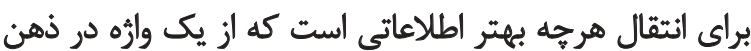

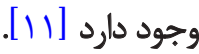

در خصوص ييوند كلمات در ذهن و روابط بين آنها، تحقيقات

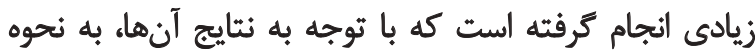

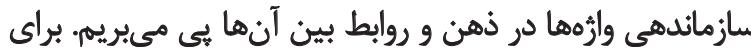

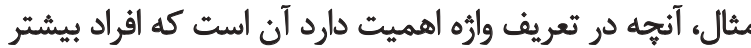

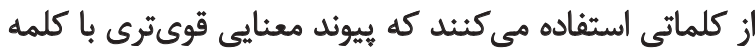

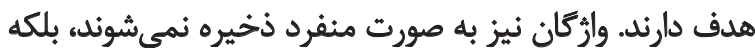

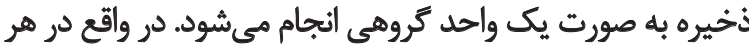

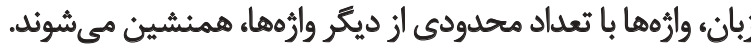

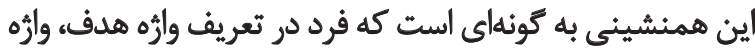

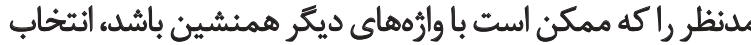

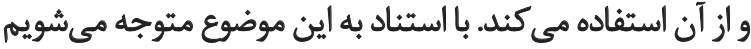

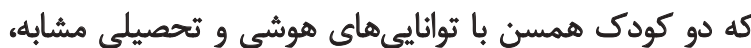

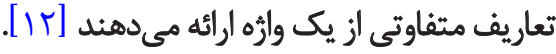

براى ارائه يك تعريف قابل قبول، فرد نياز دارد كه علاوه بر

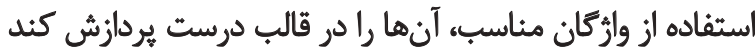

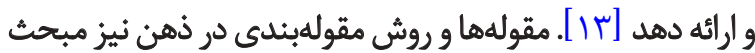

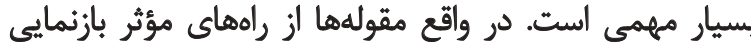

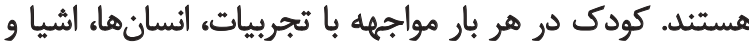

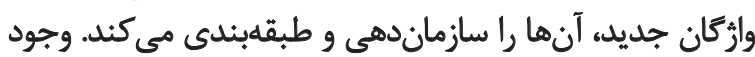

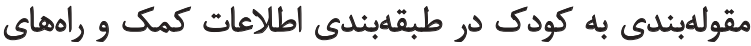

1. Mental lexicon 


\section{ووش بروسى}

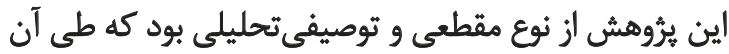

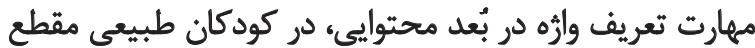

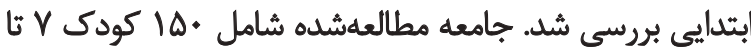

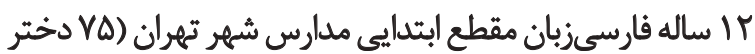

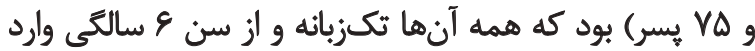

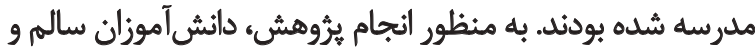

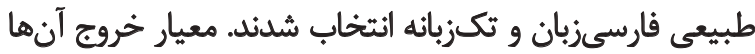

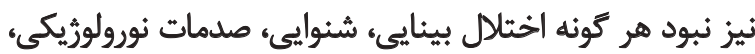

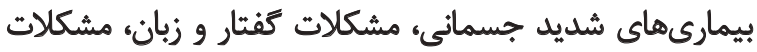

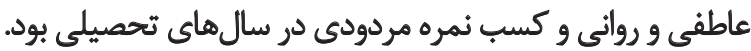

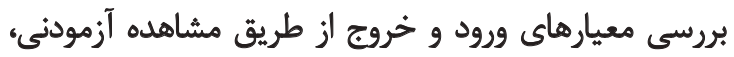

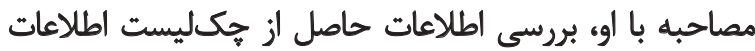

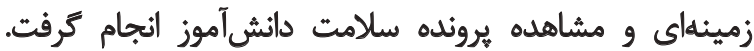

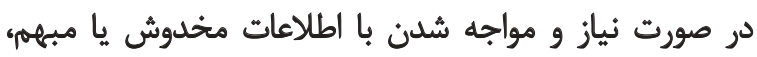

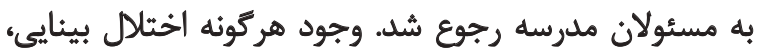

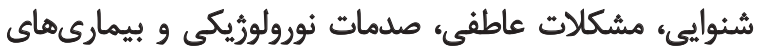

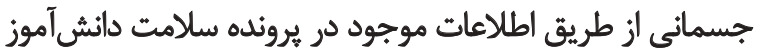

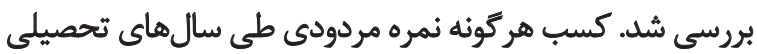

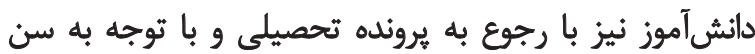

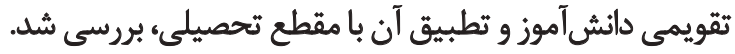

ازز طريق مصاحبه با آزمودنى و يرسيدن سؤالاتى متناسب باسن

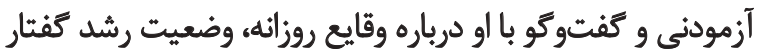

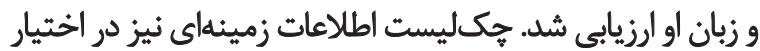

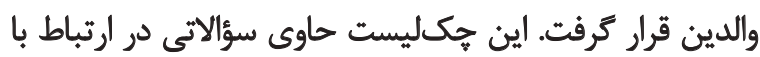

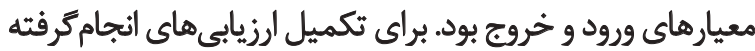

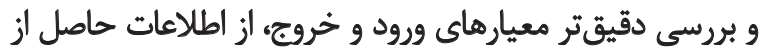

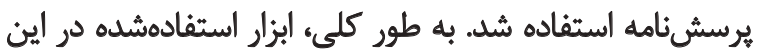

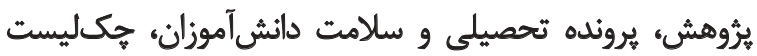

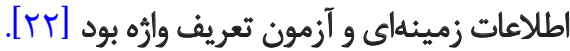

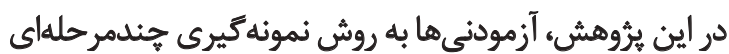

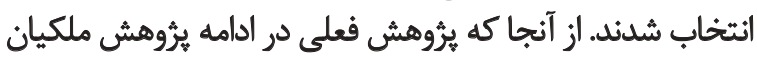

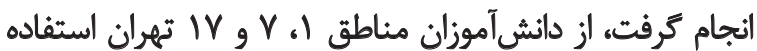

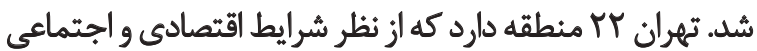

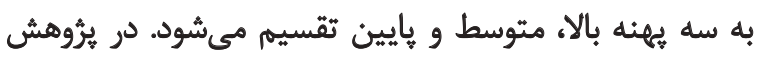

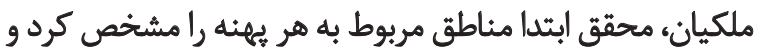

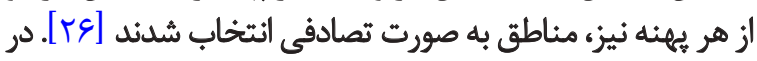

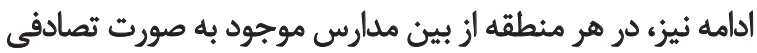

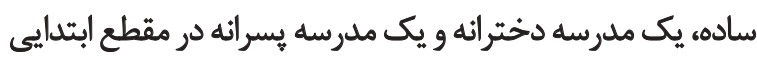

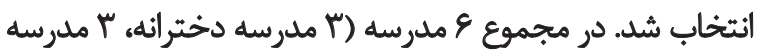

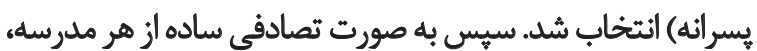

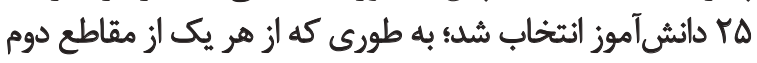

مى شود. همجينين توانايى فرازبانى و سطح تحصيلات نقش مهريى

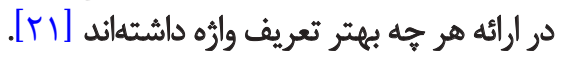

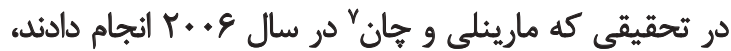

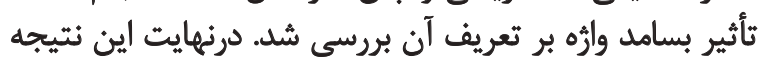

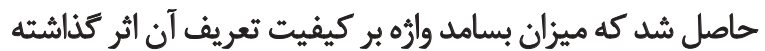

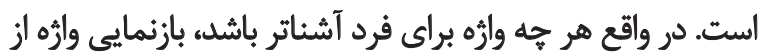

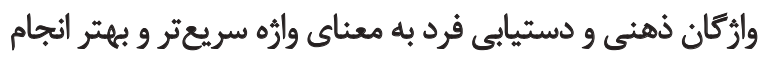

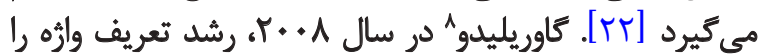

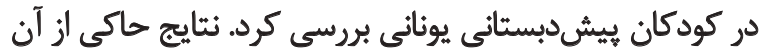

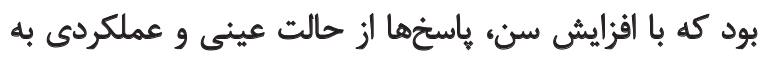

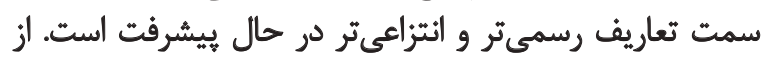

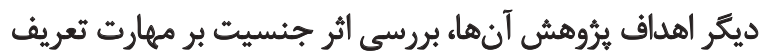

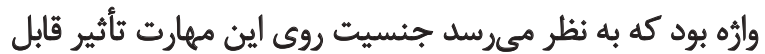

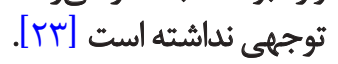

در ايران محمدى در سال I| + ك، مهارت تعريف وارثه كودكان

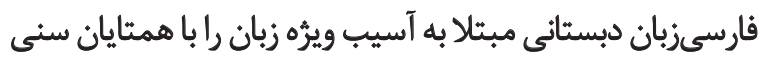

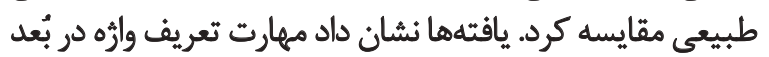

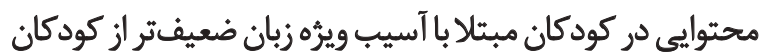

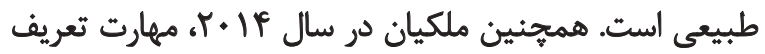

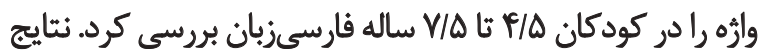

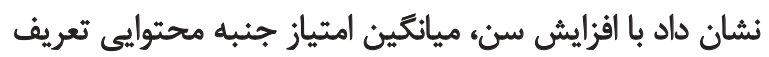

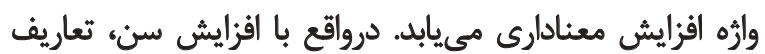

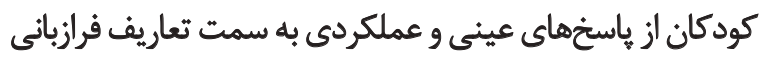
بيش مىرود كه از نظر محتوا و ساختار رشد ئد يافتهاند.

مهارت تعريف وارثه ازجمله مهارتهايى است كه در كشورها و وندان

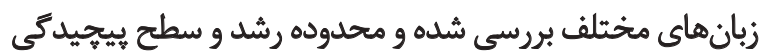

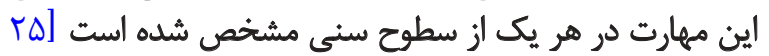

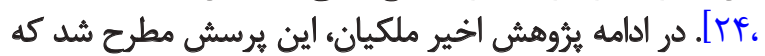

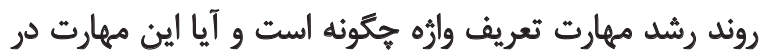

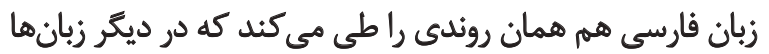

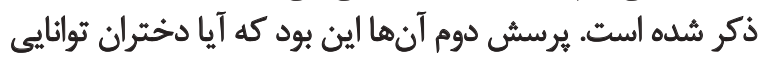
متفاوتى را نسبت به بـران در تعاريف وارث ارائه مى دهند. در بيشتر تحقيقاتى كه در اين حوزه انجام كرفته، براى براي

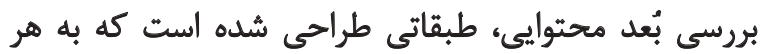

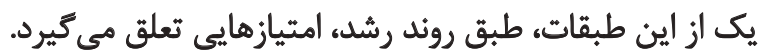

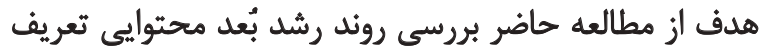

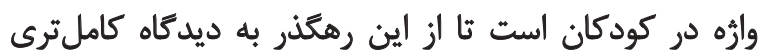

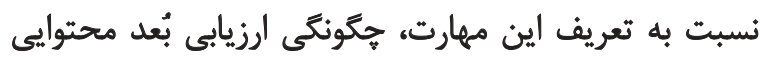

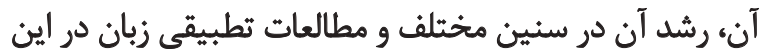

$$
\text { زمينه برداخته شود. }
$$


تعريف عملكردى، تعريف وارٔه هدف به صورت بيان عملكرد يا نحوه استفاده از آن است. براى مثال، در تعريف سيب بيان شودي:

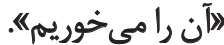

تعريف عينى، تعريف وارهه هدف از طريق بيان ويزٔكى هايى از

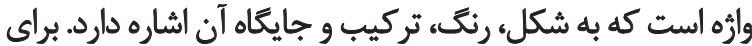

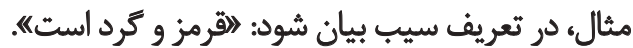
تعريف تداعى، تعريف يك وارثه از طريق بيان جفتى از آن وارثه

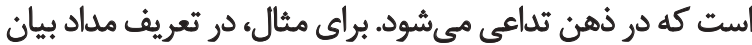

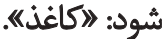

تعريف تشبيهى، تعريف يك وارهه با بيان واره ديكرى است كه با آن مرتبط است. براي مثال، در تعريف اسب بيان شود: المثل كاويه. تعريف مقوله كلى ساده، تعريف يك وارٔه از طريق وارثاى است

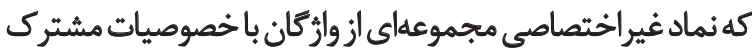
است. براى مثال، در تعريف انار بيان شود: ليك خوراكى استها. تعريف مقوله اختصاصى، تعريف واره از طريق وارثماى است

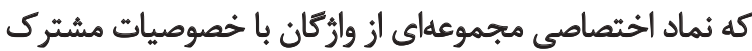
است. براى مثال در تعريف اسب بيان شود: لايك حيوان است إتهات تعريف مترادف، تعريف يك وارثه با بيان واره هممعنى است. براى مثال، در تعريف دكتر بيان شود: لإيزشك) بيان تعريف به صورت تركيبى نوع اول، تعريف يك واره با به كاركيرى

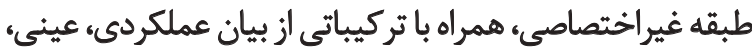

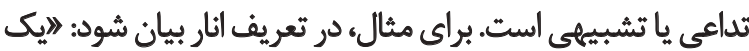

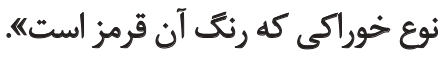

تعريف به صورت تركيبى نوع دومه تعريف يك وارثه با

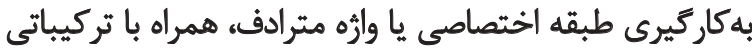

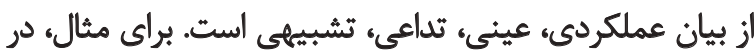

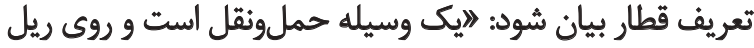

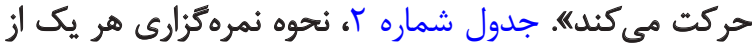

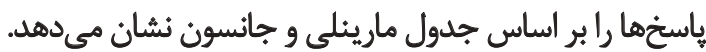

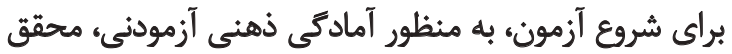

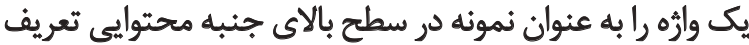

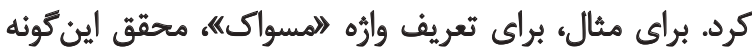

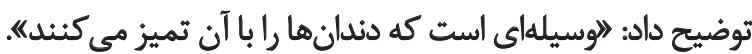

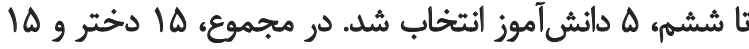

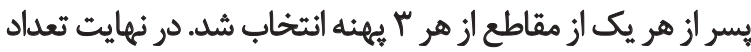

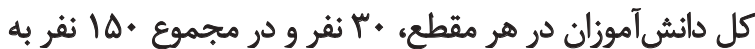

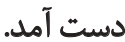

محمدى و همكاران آزمون تعريف واره را طراحى كردهاند.

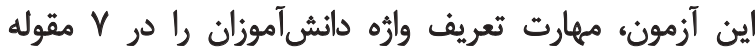

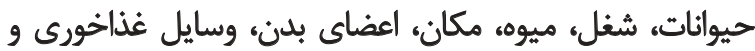

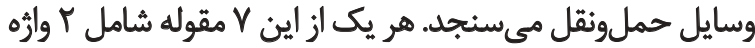

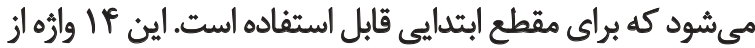

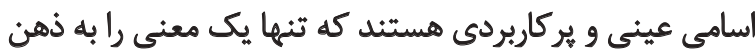

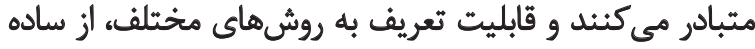

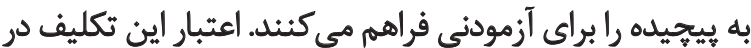

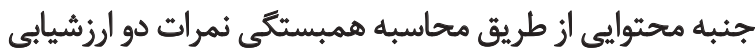
مستقل به دست آمده است.

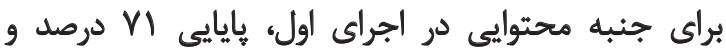

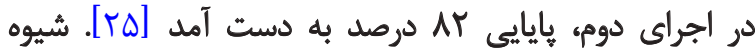

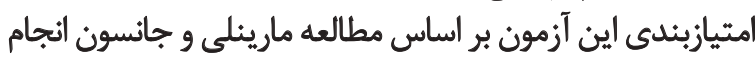

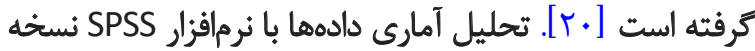

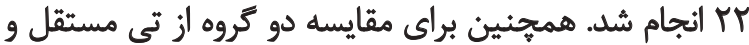

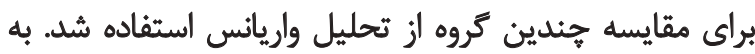

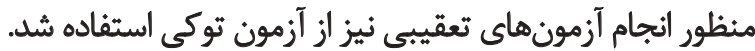

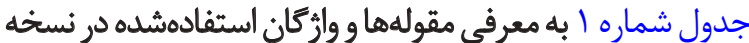

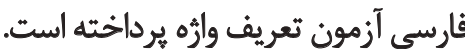
تعريف والره و انواع باسخهاي محتوايي منظور از جنبه محتوايي، بيان مختصات معنايى يك وارهه است

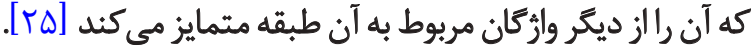

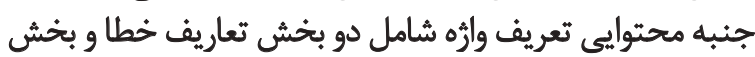

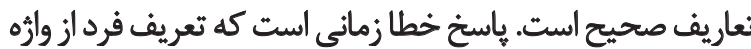

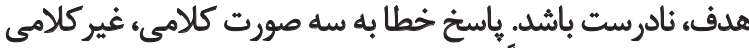

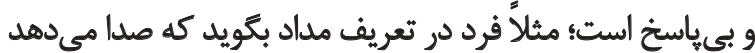

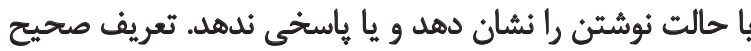

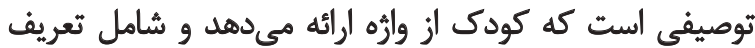

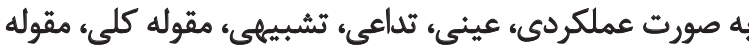

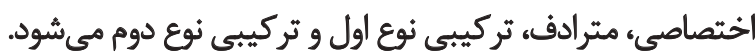

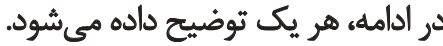

جدول ا. مقولات و اسامى استفادهشه در آزمون تعريف وارهه

\begin{tabular}{|c|c|c|c|c|c|c|c|}
\hline مكان & هيوه & شغل & اتدام ببن & وسايل حملونقل & هيواتثات & وسايل غذاخورى & مقولاث \\
\hline مدرسه & سيب & مeملم & دست & قطار & كلاغ & قاشق & \multirow{2}{*}{ وازٔهها } \\
\hline سجدل & انتار & دكتر & $\downarrow$ & هواييما & اسب & ليوان & \\
\hline
\end{tabular}


جدول Y. طبقهندي ياسخها و امتيازات مربوط به جنبه محتوايي تعريف والوه

\begin{tabular}{|c|c|c|c|}
\hline مثال & امتياز & افواع ياسخها & رديف \\
\hline مداد جيه: نشاني دادن حالث نوبل نوشتن & + & خطا (تعريف نادرست، بلدون ياسخ، ايما و اششاره كردن) & 1 \\
\hline كليب جيه؟ آن آن را هى حُوريهم. & 1 & عملكردى (بيان عملكرد يا هكوئكى استفاده از شى) & $r$ \\
\hline سيب جيه جيه قرمز و كرد است. & 1 & عينى (ييان اجزا، رئك، شكل، مكان و ...) & $r$ \\
\hline مداد جيه؟ كافٔذ. & 1 & 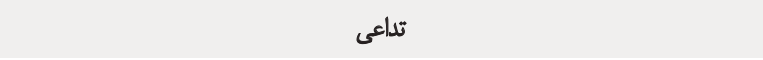 & f \\
\hline 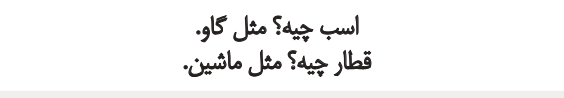 & r & تشييه (قياس معنايف) & $\Delta$ \\
\hline أثار جيهي يك ئوراكى است. & r & 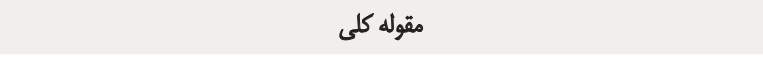 & 8 \\
\hline سيب جيهيه؟ يك حيولى ميوه است. & $r$ & مقوله اختصاصى & $\checkmark$ \\
\hline دكتر كيه؟ يزشك. & r & 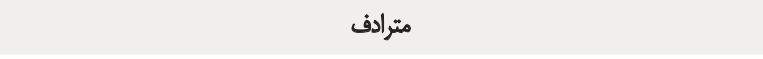 & $\wedge$ \\
\hline انار جيه؟ يك ثتع خوراكيه كه رنق آن قرمز است. & f & تركيبى نوع اول (هر تركيبي از عملكردى، عينى، تشبييهى، تداعى و مقوله كلى) & 9 \\
\hline قطار جيه؟ يك وسيله حملونقل الست و روى ريل حركت مىكند. & $\Delta$ & تركييى نوع دوم (نام بردن مقوله خاص يا تام مترادف به همراه حهاقل يك مختصه ديكى) & 1. \\
\hline
\end{tabular}

توانبخننى

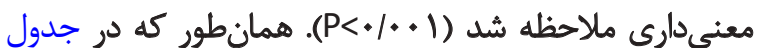

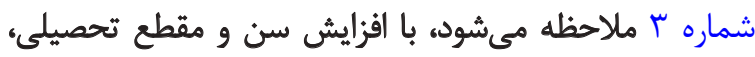
ميانكين امتياز ياسخ محتوايى افزايش مي يابد فيد.

براي مقايسههاي جفتى از آزمون تعقيبى توكى استفاده

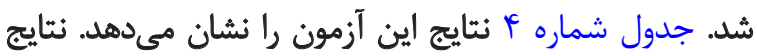

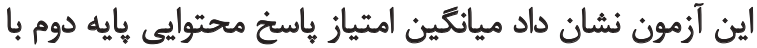

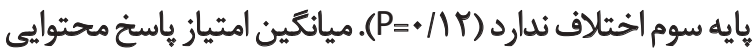

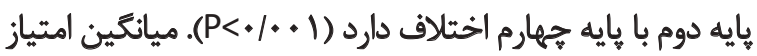

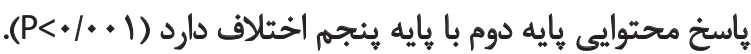

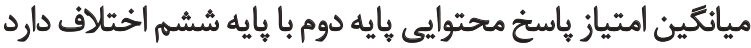

$$
(P<\cdot 1 \cdot 1)
$$

ميانكين امتياز باسخ محتوايع بايه سوم با بايه دوم اختّلاف

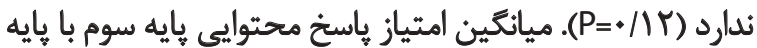

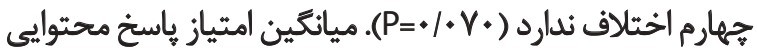

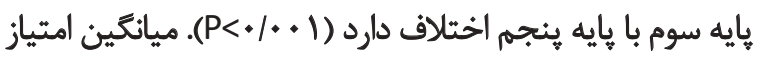

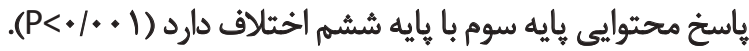

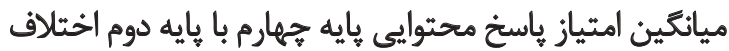

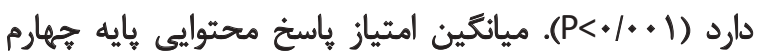

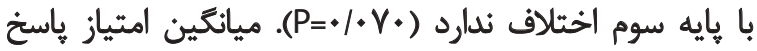

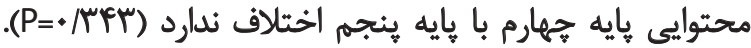

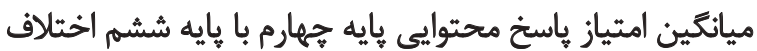

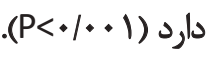

بعد از رفع ابهام و آمادكى ذهنى دانش آموز، از تكليف تعريف وارثه

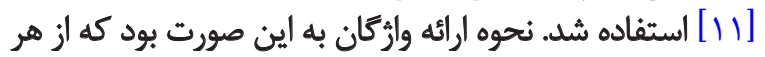

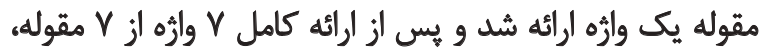

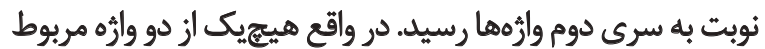

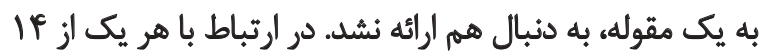

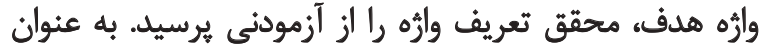

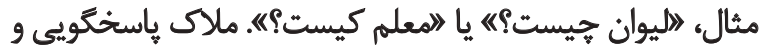

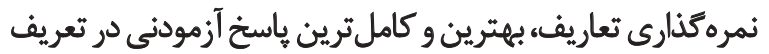

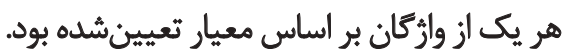

ياثتلها

با توجه به جدول نمرهدهى كه بيشتر ذكر شئ شده ابتدا نمره

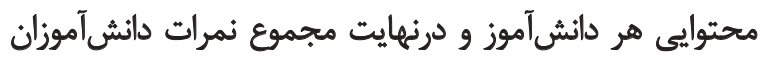

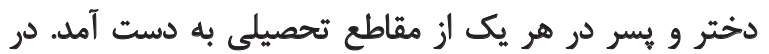

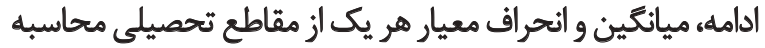

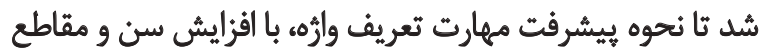

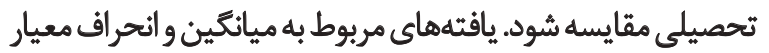
جنبه محتوايى تعريف وارثه در جدول شماره بارئ آرائه شده است. براى مقايسه نمره بخش محتوايى دختران و وِيسران در سنين

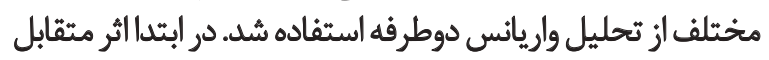

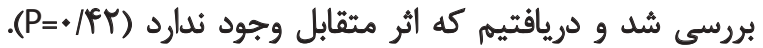
سيس اثرات اصلى بررسى شد. در مقاطع دوم تا ششم اختلاف متاف 


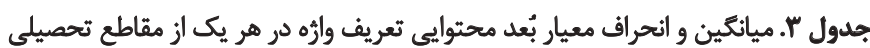

\begin{tabular}{|c|c|c|c|c|c|}
\hline \multicolumn{2}{|c|}{ فاصله اطمينان ه9 درصد } & \multirow{2}{*}{ أنحراف معيار } & \multirow{2}{*}{ مياتكين } & \multirow{2}{*}{ تعداد } & \multirow{2}{*}{ جايه } \\
\hline حد بايين & حد بالا & & & & \\
\hline \multicolumn{6}{|c|}{ جنبه محتوايى } \\
\hline TNE. & $19 / 79$ & V/T & $m / l$ & r. & دوم \\
\hline$r \Delta / A V$ & TW/TE & $I T / N \Delta$ & $r v / \Delta r$ & r. & سوم \\
\hline$n T / q V$ & $r \Delta / r q$ & $1 F / \pi$ & rqger & $r \cdot$ & جهارم \\
\hline$p q / \gamma$ & $p y / \cdot q$ & $16 / 199$ & ra/f. & $r_{*}$ & هينجم \\
\hline$\Delta N F V$ & PQ/Ne & q/FA & $\Delta r / I V$ & $r+$ & شش \\
\hline$f * / q$. & $m V / \circ \Delta$ & $10 / 19$ & rNQU & 10. & كل \\
\hline
\end{tabular}

توانبخننى

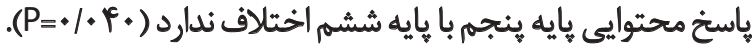
ميانغين امتياز ياسخ محتوايي يايه ششم با بايه دوم اختيلاف

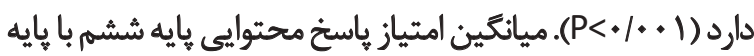

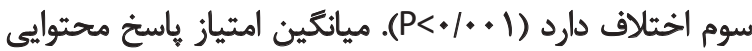

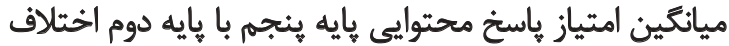

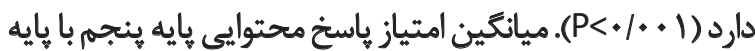

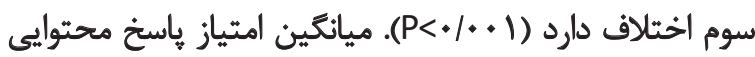

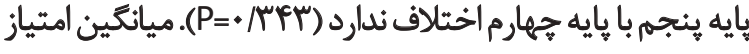

جدول F. نتايج آزمون تعقيبى توكى براى مقايسهاي جفتى

\begin{tabular}{|c|c|c|}
\hline معنادارى & هايه r & بايه 1 \\
\hline.$M$ & $r$ & \multirow{4}{*}{$r$} \\
\hline$\%$ & f & \\
\hline$\%$ & $\Delta$ & \\
\hline$\%$ & 9 & \\
\hline.$M$ & $r$ & \multirow{4}{*}{$r$} \\
\hline$\% \gamma$ & $r$ & \\
\hline$\%$ & $\Delta$ & \\
\hline$\%$ & 8 & \\
\hline$\%$ & $r$ & \multirow{4}{*}{$f$} \\
\hline$\% r$ & $r$ & \\
\hline.$/ \pi$ & $\Delta$ & \\
\hline$\%$ & 8 & \\
\hline$\%$ & r & \multirow{4}{*}{$\Delta$} \\
\hline$\%$ & $r$ & \\
\hline . Me & $p$ & \\
\hline$\%$ & 9 & \\
\hline$\%$ & r & \multirow{4}{*}{8} \\
\hline$\%$ & $r$ & \\
\hline$\%$ & r & \\
\hline$\%$ & $\Delta$ & \\
\hline
\end{tabular}


جدول ه. ميانكين توزيع أواع باسخهاي جنبه محتوايى تعريف وازه

\begin{tabular}{|c|c|c|c|c|c|c|c|c|c|c|}
\hline تركيبى نوع دوم & تركييى ثوع اول & مترادف & مقوله اختصاصى & مقوله كلى & تشييه & تداعى & عينى & عملكردى & خطا & مقطع \\
\hline \multicolumn{11}{|c|}{ كل } \\
\hline.$/ 94$ & V/Ar & . & $+/ \pi Y$ & שו/. & . & . &.$/ 1$ & $1 . / 8 v$ & "ו/. & $r$ \\
\hline $1 / M$ & $r / q V$ & . & 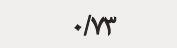 & r/r/. & ז & . & . $/ \Delta V$ & $v /$. &.$/ 4$ & $r$ \\
\hline$r / T V$ & $r / q$. & . &.$/ \Delta$. &.$/ r$ & . & . & .11 & $\Delta M$ &.$\mu$ & $i$ \\
\hline T/AT & r/qr & - & $1 / r$. & .1 & - & - &.$/ 14$ & $\% \cdot v$ & 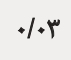 & $\Delta$ \\
\hline$\Delta / A_{0}$. & $\Delta / \psi^{*}$ & . & س & $\% / v$ & . & . & $\%$ & M. &.$/ V$ & $\&$ \\
\hline$r / . \%$ & $r / \Lambda)$ & $\%$ &.$/ 90$ & .110 & $\%$ & . &.$/ 19$ & a/u & $\cdot|r|$ & كل \\
\hline
\end{tabular}

توانبخننى

و درنهايت با اقزايش سن، كاهش يافت. ميزان استفاده از دو ياسخ تركيبى نوع اول و نوع دوم نيز افزيش سيش يافيت.

نتايج اين مطالعه با بسيارى از مطالعات انجامكرفته در ارتباط با

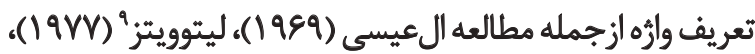

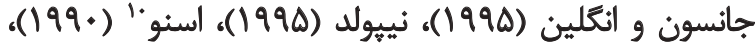

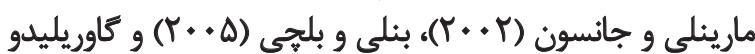

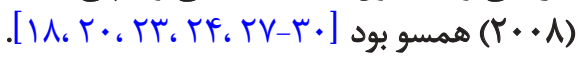
كودكان معمولاً براى كسب دانش كامل و مناسب از وازثكان،

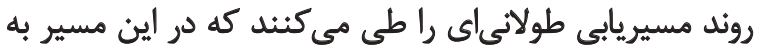

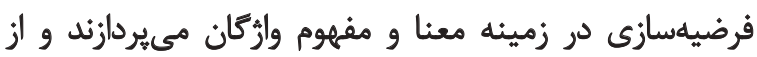

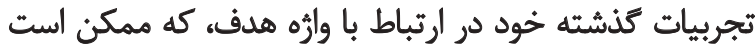
در شرايط و موقعيتهاي مختلف كسب كرده باشند، استفاده

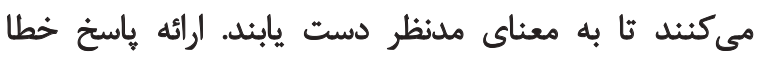

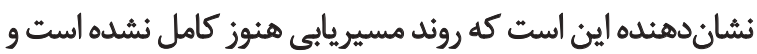

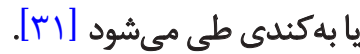

كاهش ياسخ خطا نشان ميدهد كه روند مسيريابي كودى

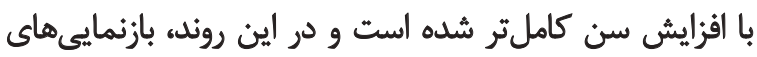

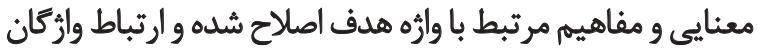

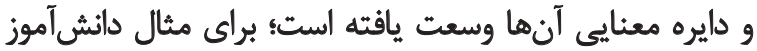

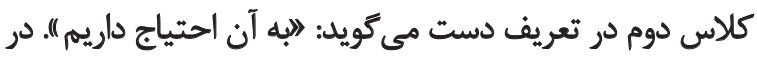

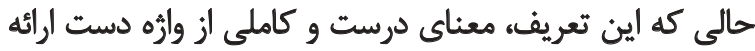

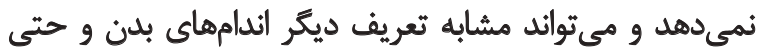

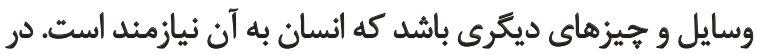

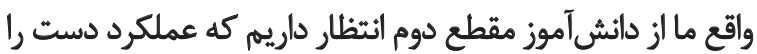

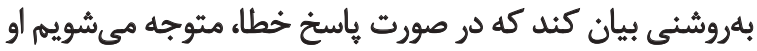

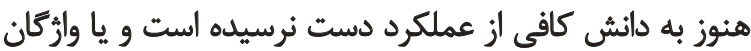

9. Litowitz

10. Snow
بايه ششمر با بايه جهارم اختلاف دارد (1 + + (P> ). ميانكين امتياز

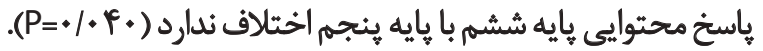
در مجموع، نتايج حاكى از آن است كه باستخهاى دانشآموزلن

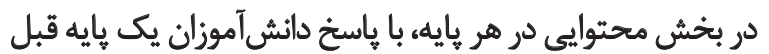

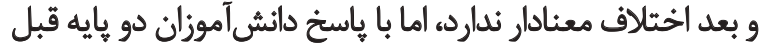
و بعد اختلاف معنادار دارد.

جدول شماره ه، ميانغين توزيع هر يك از ياسخهاى جنبه

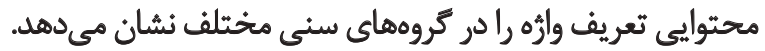
همان طور كه در جدول شماره ه ملاحظه مي مشوده دانش آموزان مقطع دوم از باسخهاى عملكردى بيشترى استثفاده كردهاند و

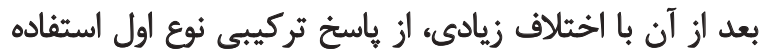

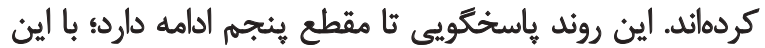

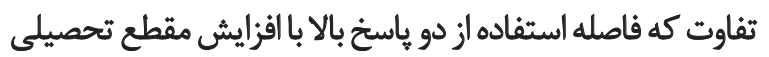

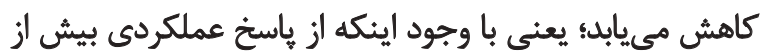

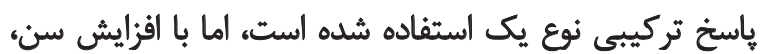

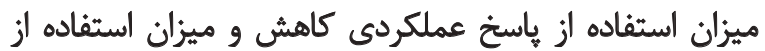

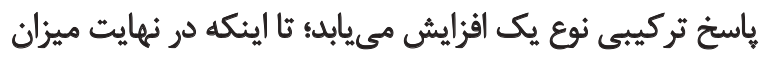
استفاده از ياسخ تركيبى نوع دوم در مقطع ششم به بي بيشترين

ميزان ميرسد. $\leftrightarrow$

اين ثيروهش با هدف مقايسه و بررسى روند رشد تعريف وائه در

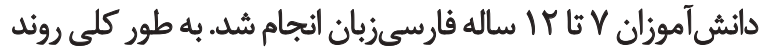

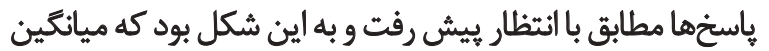

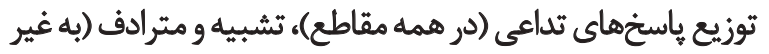

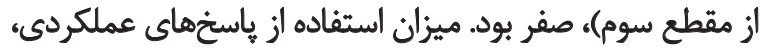

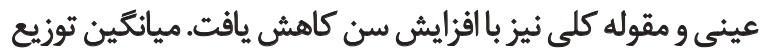

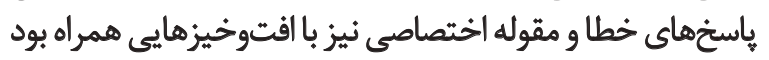




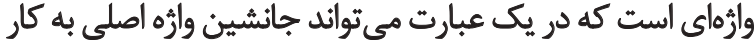

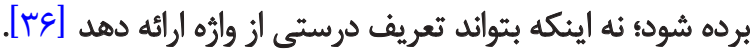

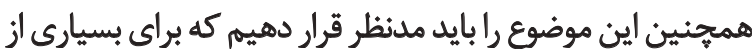
وارثان عينى، نمى توان وازٔكان مترادف ييدا كرد.

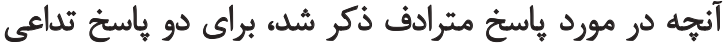

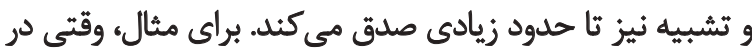

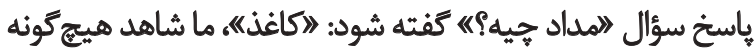

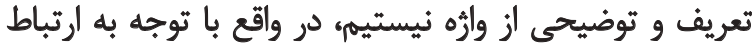

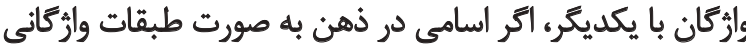

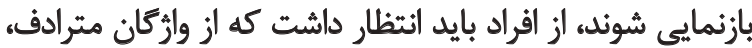

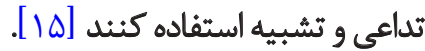

در واقع تداعى، شيوهاي است كه فرد با استفاده از آن وازثًان

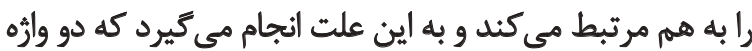

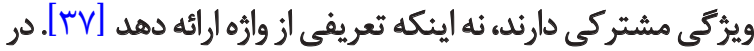

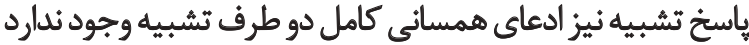

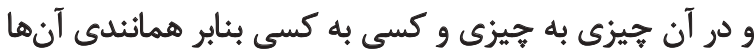

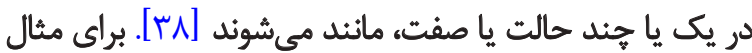

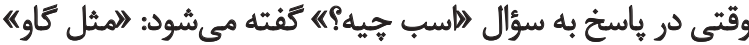

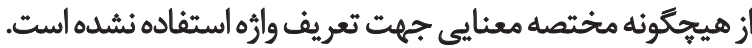

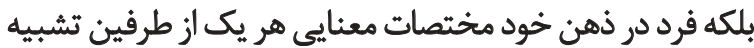

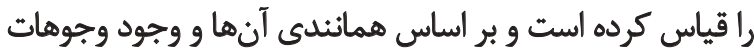

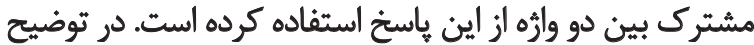

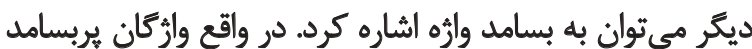

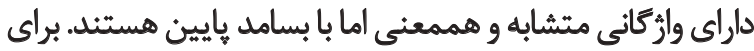

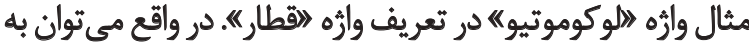

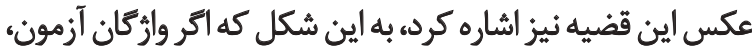

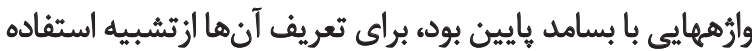

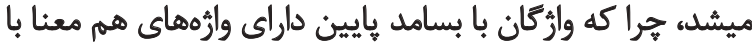

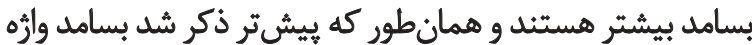

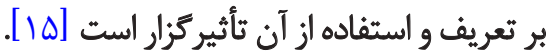

در اين آزمون تنها از اسامى استفاده شده است و وازمههايى

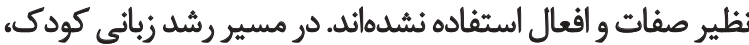

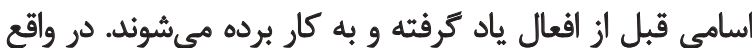

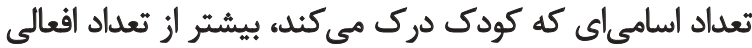

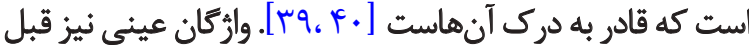

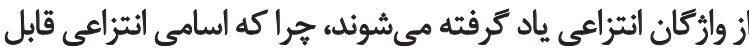

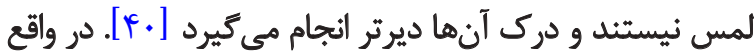

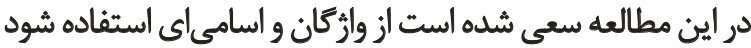

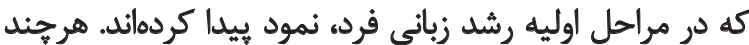

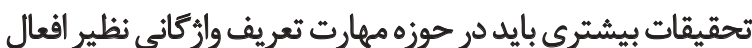

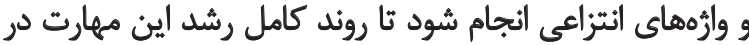
كودكان فارسىزبان به دست آيدا
مدنظر براى تعريف صحيح از وارٔه را نيافته است.

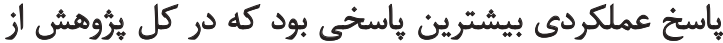

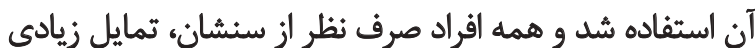

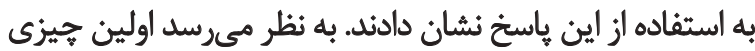

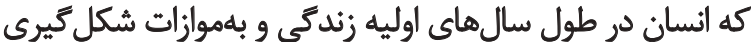

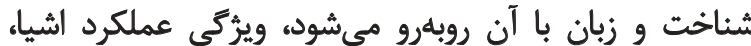

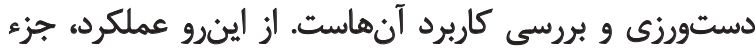

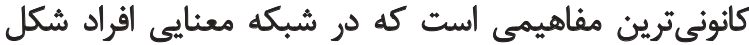

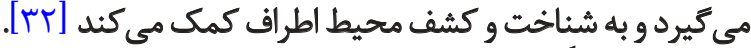

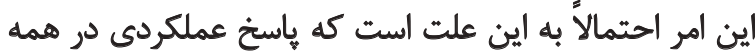

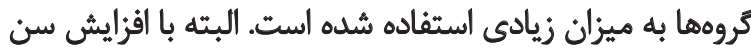

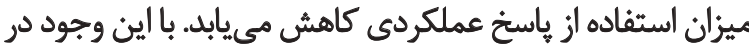

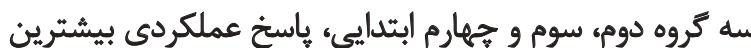
ياسخ استفادهده در دانش آموزان بوده است.

كاهش استفاده از ياسخ عملكردى، ديدگًاه روند رشد وارثه

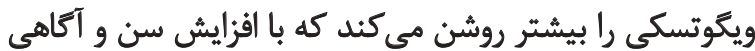

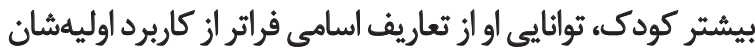

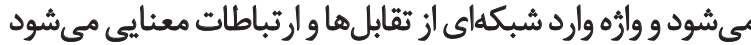

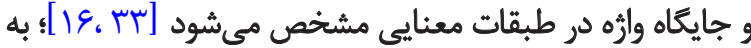

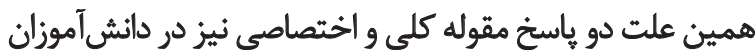

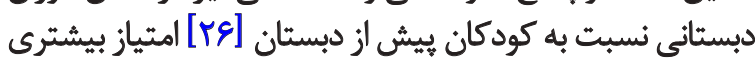
كسب كرده است.

ميانَّين امتياز دو ياسخ تركيبى نوع اول و دوم با افزايش سن

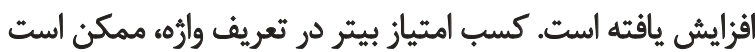

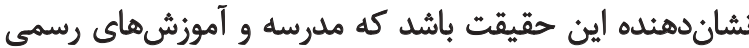

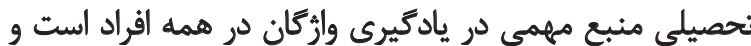

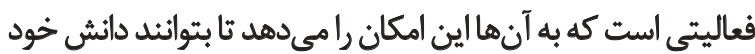

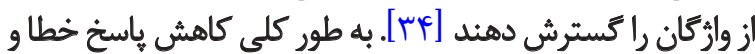

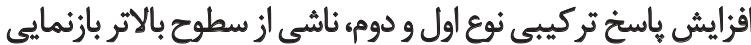

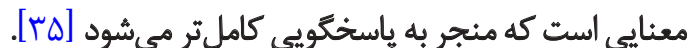

ميانكين امتياز عاسخ مترادف و تشبيه نُيز بسيار بايين بود.

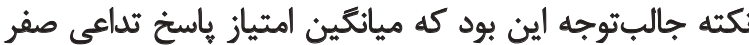

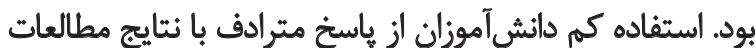

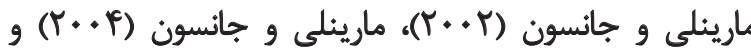

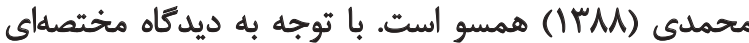

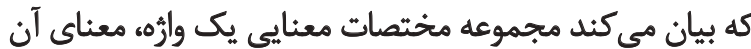

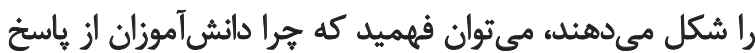

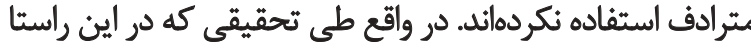

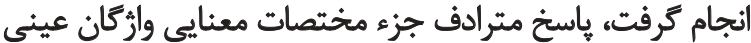

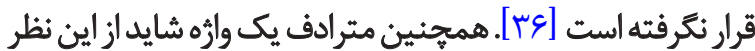

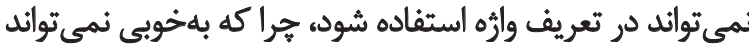

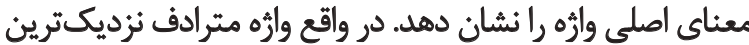


ييشرفت مهارت تعريف كردن كودكان مي تواند عملكرد تحصيلى

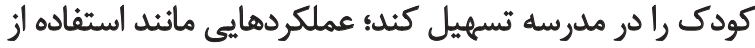

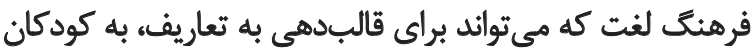

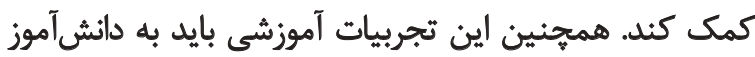

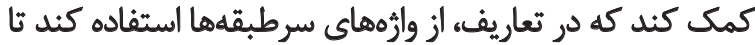
بتواند مهارت طبقهبندى را در تعريف وارثه ياد بـيخيرد.

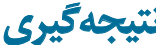

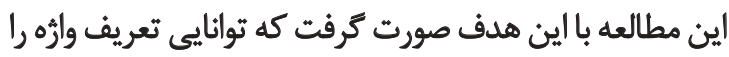

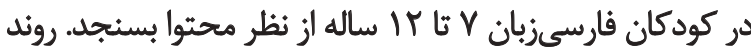

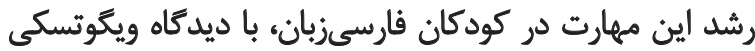

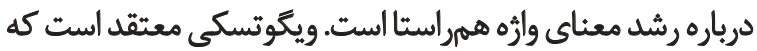

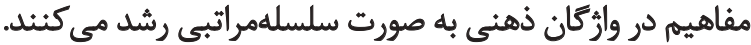

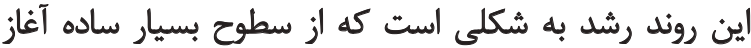

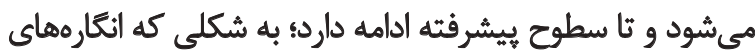

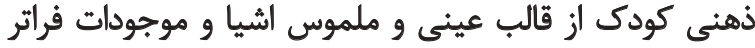

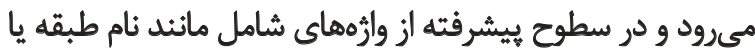
مقوله فراكير استفاده مى كند.

به طور كلى در بخش محتوايى اين نتيجه حاصل شد كه با مبا افزايش سن و مقطع تحصيلى دانشآموزان، ميانئين امتياز آنياز

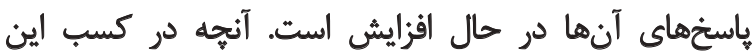

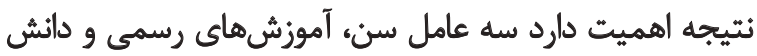

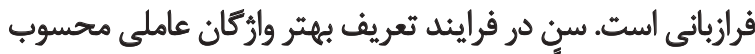

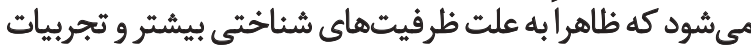
طولانىمدت

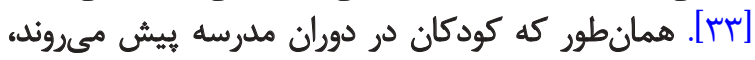

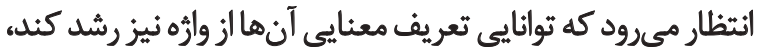

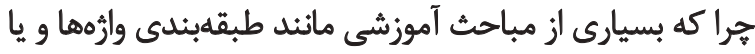

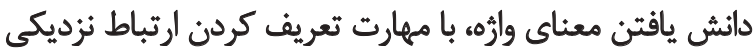

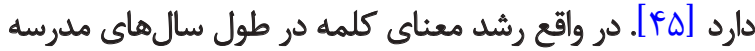

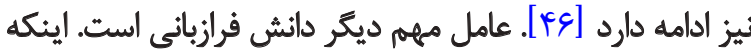

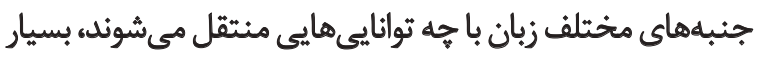

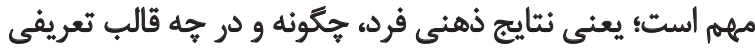

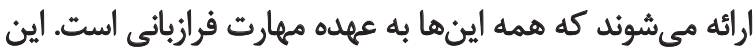

مهارت نيز با افزايش سن كامل تر مىشود [سبـ]

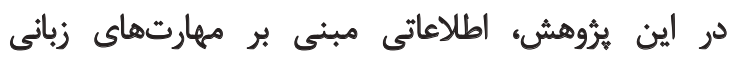

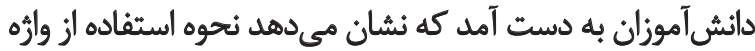

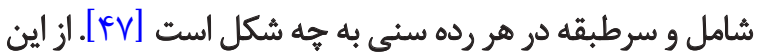

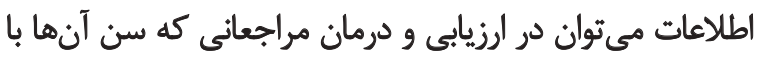

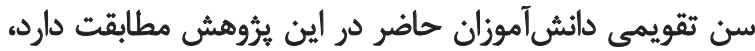

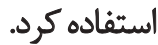

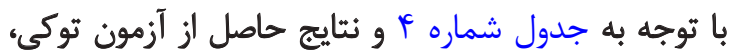
"ياسخهاى دانشآموزان در بخش محتوايى در هر ثايه، با ياسخ

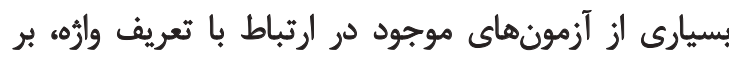

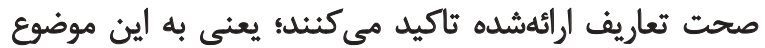

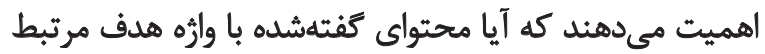

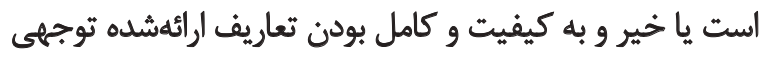

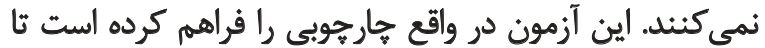

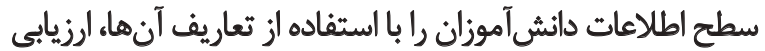

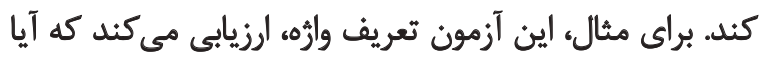

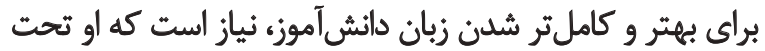

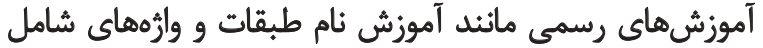
قرار بكيرد يا خير.

يافتهها نشان مىدهد تعاريف عملكردى در طول سالهاى

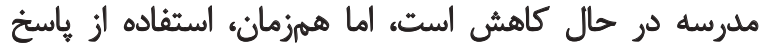

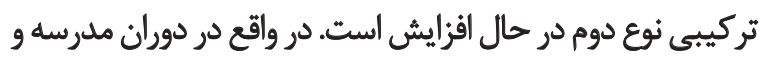

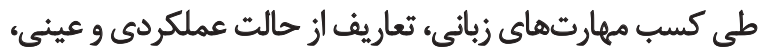

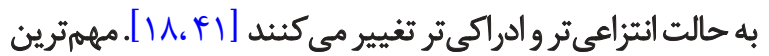

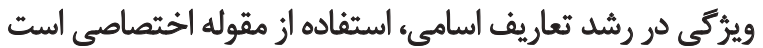

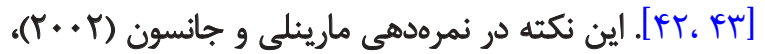

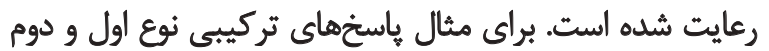

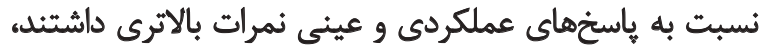

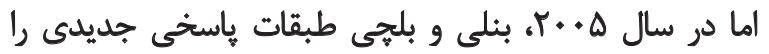

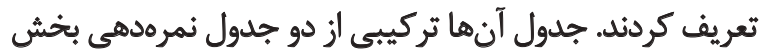

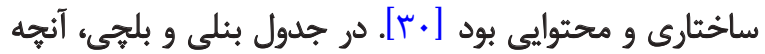

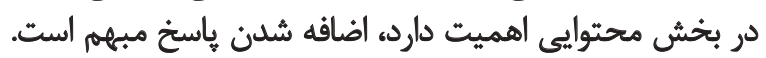

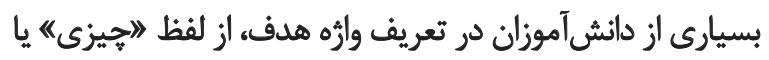

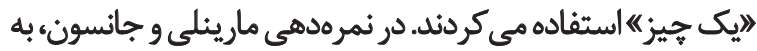

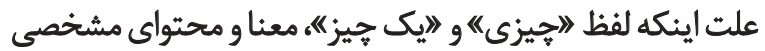

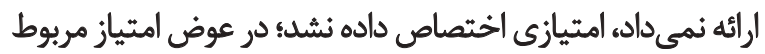
به اين لفظظ در بُعد ساختارى مدنظر قرار كرفت يكى از ديدكاههاى موجود مبنى بر تشكيل مفاهيم و معناى

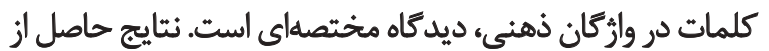

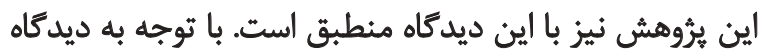

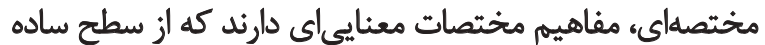

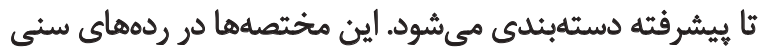

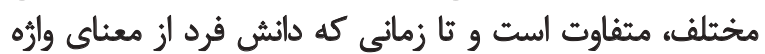

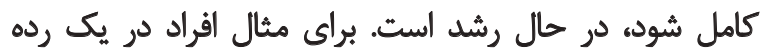

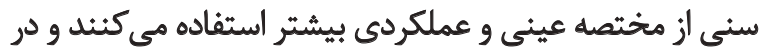

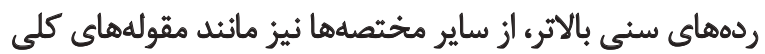

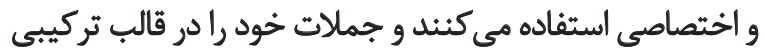
نوع اول و يا تركيبى نوع دوم ارائه مى دهند.

يافتههاى حاصل از اين برزوهش، از لحاظ آموزشى نيز بسيار

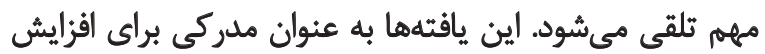

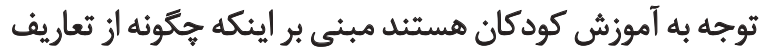

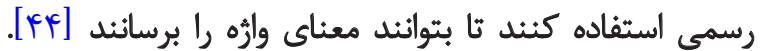




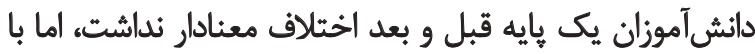

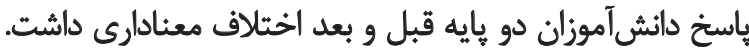

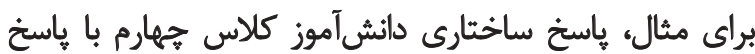

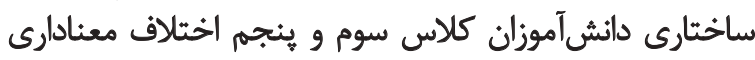

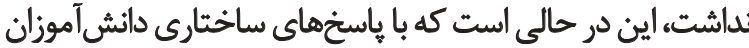

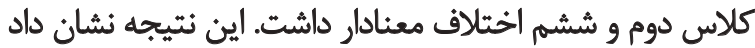
مهارت تعريف واره بهكندى رشد مي كنئد

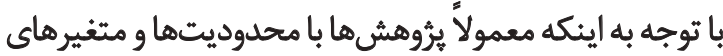

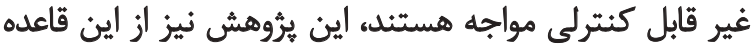

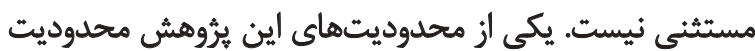

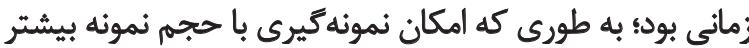

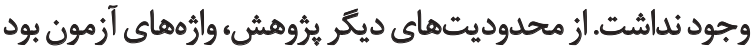

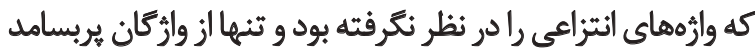

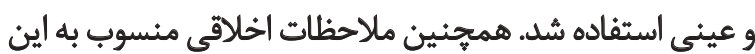

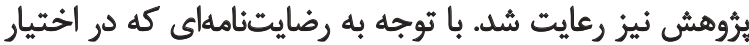

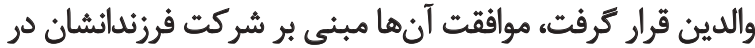

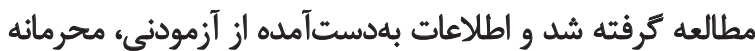

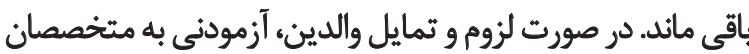

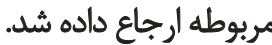

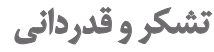

اين مقاله از بايان نامه كارشناسى ارشد نويسنده اول در رشته

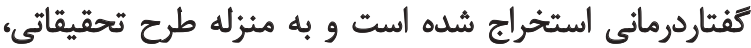

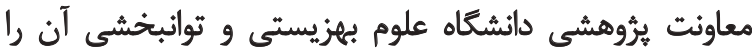

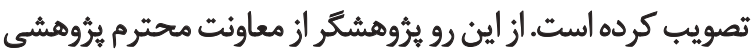

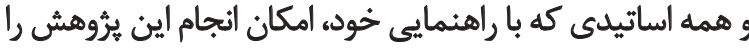

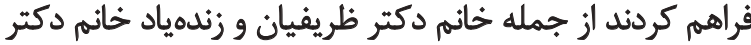

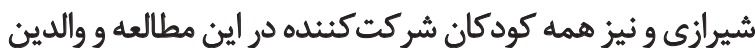

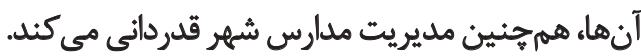




\section{References}

[1] Altenberg B, Granger S. Recent trends in cross-linguistic lexical studies. In: Altenberg B, Granger S, editors. Lexis in contrast: Corpus-based approaches. Amsterdam: John Benjamins Publishing Company; 2002. doi: 10.1075/scl.7.04alt

[2] Ramezani S, Nilipour R, Yadegari F, Rahgozar M. [The effect of phonological encoding complexity on speech fluency of stuttering and non-stuttering children (Persian)]. Archives of Rehabilitation. $2012 ; 12(4): 42-7$

[3] Pahlavannezhad MR, Moulavi VA. The effect of frequency, semantic priming and repetition priming on lexical access. Journal of Human Sciences. 2008; 56:29-40

[4] Hoff E. Language development. Boston: Cengage Learning; 2013

[5] Paul R. Language disorders from infancy through adolescence: Assessment \& intervention. Amsterdam: Elsevier Health Sciences; 2007.

[6] Malrieu JP. Evaluative semantics: Cognition, language and ideology. Abingdon: Routledge; 2002.

[7] Gaskell MG, Altmann G. The Oxford handbook of psycholinguistics. Oxford: Oxford University Press; 2007.

[8] Aitchison J. Words in the mind: An introduction to the mental lexicon. New Jersey: John Wiley \& Sons; 2012.

[9] Caramazza A. How many levels of processing are there in lexical access. Cognitive Neuropsychology. 1997; 14(1):177-208. doi: $10.1080 / 026432997381664$

[10] Smith EE, Medin DL. Categories and concepts. Cambridge: Harvard University Press; 1981.

[11] McGhee-Bidlack B. The development of noun definitions: A metalinguistic analysis. Journal of Child Language. 1991; 18(2):417-34. doi: 10.1017/s0305000900011132

[12] Vannest J, Newport EL, Newman AJ, Bavelier D. Interplay between morphology and frequency in lexical access: The case of the base frequency effect. Brain Research. 2011; 1373:144-59. doi: 10.1016/j.brainres.2010.12.022

[13] Matloubi S, Zarifian T, Shirazi TS, Bakhshi E. [Word definitional skills in school age Persian speaking children: A developmental study on form (Persian)]. Iranian Rehabilitation Journal. 2015; 13(3):103-8.

[14] Mohammad M, Nilipour R, Shirazi TS, Rahgozar M. Examining expression of lexical categories in Farsi- speaking children with specific language impairment. Journal of Speech and Language Pathology. 2013; 1(1):8-19.

[15] Marinellie SA, Johnson CJ. Nouns and verbs: A comparison of definitional style. Journal of Psycholinguistic Research. 2004; 33(3):217-35. doi: 10.1023/b:jopr.0000027963.80639.88

[16] Luria AR. Language and cognition [H. Ghasemzade Persian trans.]. Tehran: Arjmand Press; 2012.

[17] Leontjev AN. Problems of the development of the mind. Moscow: The publisher of the Academy of Pedagogical Sciences of the RSFSR; 1959
[18] Al-Issa I. The development of word definition in children. The Journal of Genetic Psychology. 1969; 114(1):25-8. doi: $10.1080 / 00221325.1969 .10533835$

[19] Skwarchuk SL, Anglin JM. Expression of superordinates in children's word definitions. Journal of Educational Psychology. 1997; 89(2):298. doi: 10.1037/0022-0663.89.2.298

[20] Marinellie SA, Johnson CJ. Definitional skill in school-age children with specific language impairment. Journal of Communication Disorders. 2002; 35(3):241-59. doi: 10.1016/s00219924(02)00056-4

[21] Benelli B, Belacchi C, Gini G, Lucangeli D. 'To define means to say what you know about things': The development of definitional skills as metalinguistic acquisition. Journal of Child Language. 2006; 33(1):71-97. doi: 10.1017/s0305000905007312

[22] Marinellie SA, Chan YL. The effect of word frequency on noun and verb definitions: A developmental study. Journal of Speech Language and Hearing Research. 2006; 49(5):1001. doi: 10.1044/1092-4388(2006/072)

[23] Gavriilidou Z. The development of word definitions in Greek Preschoolers [Internet]. 2011 [Cited 2011 September 23]. Available from: http://www.ling.ohio-state.edu/ICGL/proceedings/9_GAVRIILIDOU_KEDITED_88.pdf

[24] Nippold MA. School-age children and adolescents. Language Speech and Hearing Services in Schools. 1995; 26(4):320. doi: 10.1044/0161-1461.2604.320

[25] Mohammadi M, Nilipoor R, Shirazi TS, Rahgozar M. Semantic differences of definitional skills between Persian speaking children with specific language impairment and normal language developing children. Journal of Rehabilitation. 2011; 12(2):48-55.

[26] Malekian M, Sima Shirazi T, Zarifian T, Reza Soltani P, Dastjerdi $\mathrm{m}$. [Study of Development of word definition skill in children (Persian)]. Speech and Language Pathology. 2014; 6(1):51-60.

[27] Litowitz B. Learning to make definitions. Journal of Child Language. 1977; 4(02):289-304. doi: 10.1017/s0305000900001665

[28] Johnson CJ, Anglin JM. Qualitative developments in the content and form of children's definitions. Journal of Speech, Language, and Hearing Research. 1995; 38(3):612-29. doi: 10.1044/ jshr.3803.612

[29] Snow CE. The development of definitional skill. Journal of Child Language. 1990; 17(3):697. doi: 10.1017/s0305000900010953

[30] Belacchi C, Benelli B, Benelli B. Ambergris is not a precious fossil: the development of definitional skills. Developmental Psychology. 2005:5-10.

[31] Chan YL, Marinellie SA. Definitions of idioms in preadolescents, adolescents, and adults. Journal of Psycholinguistic Research. 2007; 37(1):1-20. doi: 10.1007/s10936-007-9056-9

[32] Nelson K. Concept, word, and sentence: Interrelations in acquisition and development. Psychological Review. 1974; 81(4):26785. doi: $10.1037 /$ h0036592

[33] Benelli B, Belacchi C, Gini G, Lucangeli D. "To define means to say what you know about things": The development of definitional skills as metalinguistic acquisition. Journal of Child Language. 2006; 33(01):71. doi: 10.1017/s0305000905007312 
[34] Miller GA, Gildea PM. How children learn words. Scientific American. 1987; 257(3):94-9. doi: 10.1038/scientificamerican0987-94

[35] Gutierrez-Cleflen VF, DeCurtis L. Word definition skills in spanish-speaking children with language impairment. Communication Disorders Quarterly. 1999; 21(1):23-31. doi: 10.1177/152574019902100104

[36] Gareth Gaskell M. The oxford handbook of psycholinguistics. New York: Oxford University. 2007.

[37] Gaskell MG. The Oxford handbook of psycholinguistics. Oxford: Oxford University Press; 2007. doi: 10.1093/oxfordhb/9780198568971.001.0001

[38] Dabiran H, Isazade M. [Smile process in persian literature (with the focus of nine books in the field of expression and rhetoric) (Persian)]. Quarterly Journal of Stylistic of Persian Poem and Prose (Bahar-e-Adab). 2013; 6(3):153-66.

[39] Nelson KA. Semantic development and the development of semantic memory. Children's Language. 1978; 1:39-80.

[40] Gentner D. Why nouns are learned before verbs: Linguistic relativity versus natural partitioning, technical report No. 257. Cambridge: Center for the Study of Reading; 1982.

[41] Storck PA, Looft WR. Qualitative analysis of vocabulary responses from persons aged six to sixty-six plus. Journal of Educational Psychology. 1973; 65(2):192-7. doi: 10.1037/h0034907

[42] Benelli B, Arcuri L, Marchesini G. Cognitive and linguistic factors in the development of word definitions. Journal of Child Language. 1988; 15(03):619. doi: 10.1017/s0305000900012599

[43] Nippold MA, Hegel SL, Sohlberg MM, Schwarz IE. Defining abstract entities. Journal of Speech Language and Hearing Research. 1999; 42(2):473-81. doi: 10.1044/jslhr.4202.473

[44] Schuster JW, Stevens KB, Doak PK. Using constant time delay to teach word definitions. The Journal of Special Education. 1990; 24(3):306-18. doi: 10.1177/002246699002400305

[45] Duncan GJ, Brooks Gunn J, Klebanov PK. Economic deprivation and early childhood development. Child Development. 1994; 65(2):296. doi: 10.2307/1131385

[46] Malekian M, Simashirazi T, Zarifian T, Rezasoltani P, Dastjerdi M. Development of word definition skill in children. Journal of Speech and Language Pathology. 2014; 1(3):51-60.

[47] A'meri H, Golfam A, Kolk H, A'shayeri H, Hagh-Shenas A M, Kord-Za'feranlou E. Inreraction of Syntactic Comprehension and Ability of Cognitive Sequence Processing in Persian Speeking Broca Aphasic Patients (Persian)]. Archives of Rehabilitation. 2008; 9(2):20-27. 
